\title{
Participation in environmental enhancement and conservation activities for health and well-being in adults (Protocol)
}

\author{
Husk K, Lovell R, Cooper C, Garside R
}

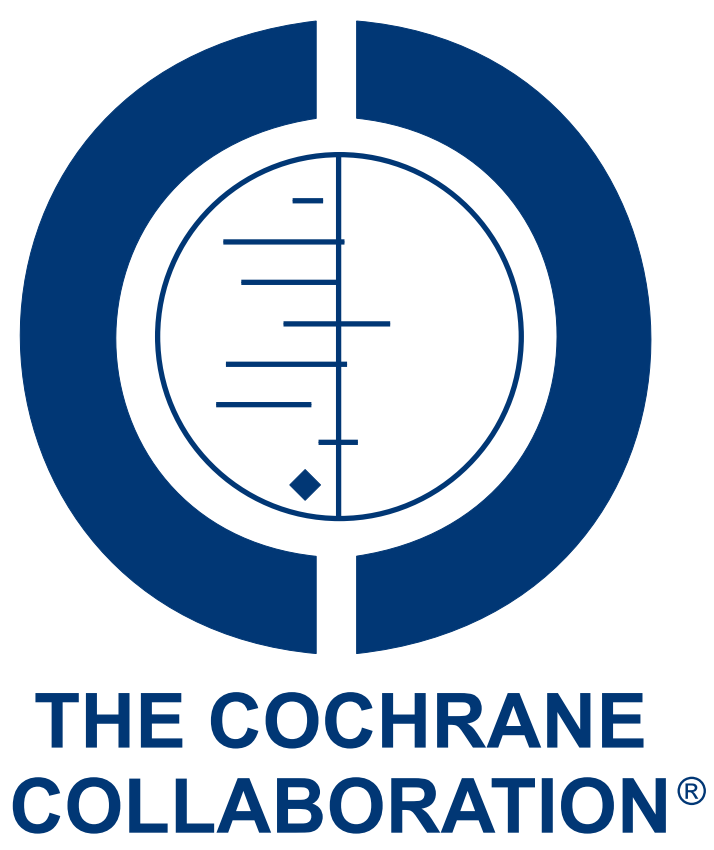

This is a reprint of a Cochrane protocol, prepared and maintained by The Cochrane Collaboration and published in The Cochrane Library 2013, Issue 2

http://www.thecochranelibrary.com

\section{WILEY}

Participation in environmental enhancement and conservation activities for health and well-being in adults (Protocol)

Copyright $\odot 2013$ The Cochrane Collaboration. Published by John Wiley \& Sons, Ltd. 
TABLE OF CONTENTS

HEADER . . . . . . . . . . . . . . . . . . . . . . . . . . . . . . . . . 1

ABSTRACT . . . . . . . . . . . . . . . . . . . . . . . . . . . . . . . . . . . . . .

BACKGROUND . . . . . . . . . . . . . . . . . . . . . . . . . . . . . . . . . . . . . . . . . . . . .

Figure 1. . . . . . . . . . . . . . . . . . . . . . . . . . . . . . . . . . . . . .

OBJECTIVES

METHODS . . . . . . . . . . . . . . . . . . . . . . . . . . . . . . . . . . . . . . 4

Figure 2. . . . . . . . . . . . . . . . . . . . . . . . . . . . . . . . . . . . . . 7

ACKNOWLEDGEMENTS . . . . . . . . . . . . . . . . . . . . . . . . . . . . . . . . . 10

REFERENCES . . . . . . . . . . . . . . . . . . . . . . . . . . . . . . . . . . . . . . 11

APPENDICES . . . . . . . . . . . . . . . . . . . . . . . . . . . . . . . . . . . . . 14

CONTRIBUTIONS OF AUTHORS . . . . . . . . . . . . . . . . . . . . . . . . . . . . . . . . . . . . . . . . . .

DECLARATIONS OF INTEREST . . . . . . . . . . . . . . . . . . . . . . . . . . . . . . . . . . . . . .

SOURCES OF SUPPORT . . . . . . . . . . . . . . . . . . . . . . . . . . . . . . . . . . . . . . . . . .

Participation in environmental enhancement and conservation activities for health and well-being in adults (Protocol)

Copyright $\odot 2013$ The Cochrane Collaboration. Published by John Wiley \& Sons, Ltd. 


\title{
[Intervention Protocol]
}

\section{Participation in environmental enhancement and conservation activities for health and well-being in adults}

\author{
Kerryn Husk ${ }^{1}$, Rebecca Lovell ${ }^{1}$, Chris Cooper $^{2}$, Ruth Garside ${ }^{1}$ \\ ${ }^{1}$ European Centre for Environment and Human Health, University of Exeter Medical School, University of Exeter, Truro, UK. \\ ${ }^{2}$ Peninsula Technology Assessment Group (PenTAG), University of Exeter Medical School, University of Exeter, Exeter, UK \\ Contact address: Ruth Garside, European Centre for Environment and Human Health, University of Exeter Medical School, University \\ of Exeter, Knowledge Spa, Royal Cornwall Hospital, Truro, Cornwall, UK. Ruth.Garside@pms.ac.uk.
}

Editorial group: Cochrane Public Health Group.

Publication status and date: New, published in Issue 2, 2013.

Citation: Husk K, Lovell R, Cooper C, Garside R. Participation in environmental enhancement and conservation activities for health and well-being in adults. Cochrane Database of Systematic Reviews 2013, Issue 2. Art. No.: CD010351. DOI: 10.1002/14651858.CD010351.

Copyright (C) 2013 The Cochrane Collaboration. Published by John Wiley \& Sons, Ltd.

\begin{abstract}
A B S T R A C T
This is the protocol for a review and there is no abstract. The objectives are as follows:

To assess the health and well-being impacts on adults following participation in environmental enhancement and conservation activities.
\end{abstract}

\section{B A C K G R O U N D}

\section{Description of the condition}

There is growing research and policy interest in the potential of using the environment to enhance human health and well-being (Defra 2011; Maller 2005; RSPB 2004). This is coupled with an increasing interest in the role of health in the context of global environmental agreements (Horwitz 2012; Patz 2012). Environmental enhancement or conservation activities specifically have been suggested as being beneficial across a wide range of population groups, including individuals with mental ill health (Fieldhouse 2003; Mind 2007; O'Brien 2011), children (Hermann 2006), adults (Evans 2008; Hale 2011; Moore 2006; O’Brien 2010; O’Brien 2011; Pretty 2007; Townsend 2006), and older adults (Bushway 2011; Pillemer 2010; Raske 2010). Research has indicated that participation in environmental enhancement activities may have direct and specific impacts on physical and mental health and well- being factors and behaviours. It has been suggested that these benefits may be brought about not only through increased opportunities for physical activity, but also that contact with the natural world, engagement in meaningful activities and potential for enhanced social cohesion may also improve health and well-being (Morris 2003; O’Brien 2011; Sempik 2010).

This review will assess the multiple health and well-being impacts on adults following participation in environmental enhancement and conservation activities.

\section{Description of the intervention}

A review, for the National Institute of Health and Clinical Excellence (NICE), of the literature on physical activity and environmental activities defined environmental enhancement activities as: "[Those] that involved a physical modification to the natural environment. This included studies that aimed to change an individual aspect or a set of characteristics of the natural envi- 
ronment..." (NICE 2006). The definition of 'environmental enhancement or conservation activities' used for this review is based on the above and is that in which participation (either voluntary, or non-voluntary such as Community Payback activities, but not through paid employment) is intended to improve the outdoor environment (either urban or rural) at either a local or broader level and in which active participation is required. Our definition differs in that we are considering enhancement and conservation of environments whether 'natural' or 'built'. Enhancement and conservation activities may include:

- watershed restoration;

- landcare (restoration in non-urban contexts);

- habitat restoration, including specific programmes such as 'Green Gym';

- litter picking; or

- re-greening of urban waste sites.

The spaces in which the enhancement activities may take place include:

- communal green spaces;

- public (or publicly accessible) parks and green spaces;

- school, hospital or other institutional grounds; or

- public (or publicly accessible) natural areas of urban and built environments.

Activities which do not focus on enhancing the environment, which take place in private spaces, or those in which participation has no practical element, will be excluded. The following examples of environmental conservation or enhancement related activities are excluded from inclusion in this review:

- domestic gardening (including allotments);

- care or therapeutic gardening;

- community farming; or

- environmental surveying.

Mutuality is central: activities will aim to be of benefit to all participants, including human, non-human, and to the environment in which the activity takes place (Burls 2007). In contrast to sustainability action (individual reduction in fuel use etc.), these actions have a physical, outdoor element, and thus potentially directly impact on the participants' immediate health and well-being.

\section{How the intervention might work}

It is hypothesised that participation in environmental enhancement and conservation activities may have multiple impacts to health and well-being, for example through opportunities for physical activity, stress relief, social contact and engagement, or through improved living environments. Various theoretical hypotheses have been proposed which have sought to identify or explain the mechanisms linking potential health impacts of environmental enhancement and conservation activities. The review will consider 'academic' alongside practitioner and service-provision theories.
Physical activity has been shown to impact upon health related quality of life (Bize 2007); it may therefore be a key mechanism through which humans benefit from environmental enhancement activities (Maas 2008). Additional benefits may accrue through the environment in which the activity takes place, for example it has been argued that physical activity in a natural environment is of greater benefit than that which takes place indoors (Haubenhofer 2010; Peacock 2007; Thompson Coon 2011). Outdoor environments offer greater topographical variation which may promote broader physiological benefits (Fjortoft 2001; Plante 2007).

Environmental enhancement and conservation activities when undertaken in a group or within a community have the potential to confer benefit through increased social connectivity. Self-esteem may be enhanced through engagement with valued activities to improve the locality. This may in turn further improve well-being (Sempik 2010), though could also perpetuate health inequalities. While it is recognised that not all environmental enhancement activities are voluntary (for example, those undertaken as community service), the act of volunteering to undertake meaningful activities with clear and defined benefits may have further positive impacts to health, specifically mental well-being (Musick 2003). Satisfaction (when considering factors such as presence of pleasant green spaces, litter or general state of repair) with one's living environment has been linked to well-being (Herzele 2012). It is hypothesised that activities undertaken to enhance one's living environment, whether urban or rural, may therefore result in improvements to health and well-being.

A group of academic theories suggest that humans have an innate evolutionary connection to the natural world and that contact may be of benefit to health and well-being (Wilson 1984). These connections have repeatedly been argued to reduce both mental fatigue and levels of stress (Kaplan 1989; Ulrich 1991). Given the increasing urbanisation of the social world and the declining contact with natural environments (Beatley 2011; Lee 2011), arguments have been forwarded citing the potential harm inherent in this separation (RSPB 2004). Attention restoration theory and psychophysiological theories suggest that the natural environment is effective in promoting recovery from fatigue and stress (both direct and indirect) (RSPB 2004). However, whilst popular, there is increasing critique of these theories (Joye 2011).

A group of practitioners involved in environmental conservation activities has been convened to form a Project Reference Group, and will help to surface the 'everyday' theories of intervention effect used to justify and support policy and practice associated with environmental enhancement (see Appendix 1). These mechanisms are summarised in an initial conceptual framework (Appendix 2; Figure 1). This was developed through an initial reading of the text and consultation with the Project Reference Group, and will be developed through the review process. We have used the 'Five Ways to Wellbeing' as an framework through which to understand the suggested potential ways in which participating in environmental enhancement activities may impact on health and well- 
being (NEF 2011).

Figure I. Conceptual model

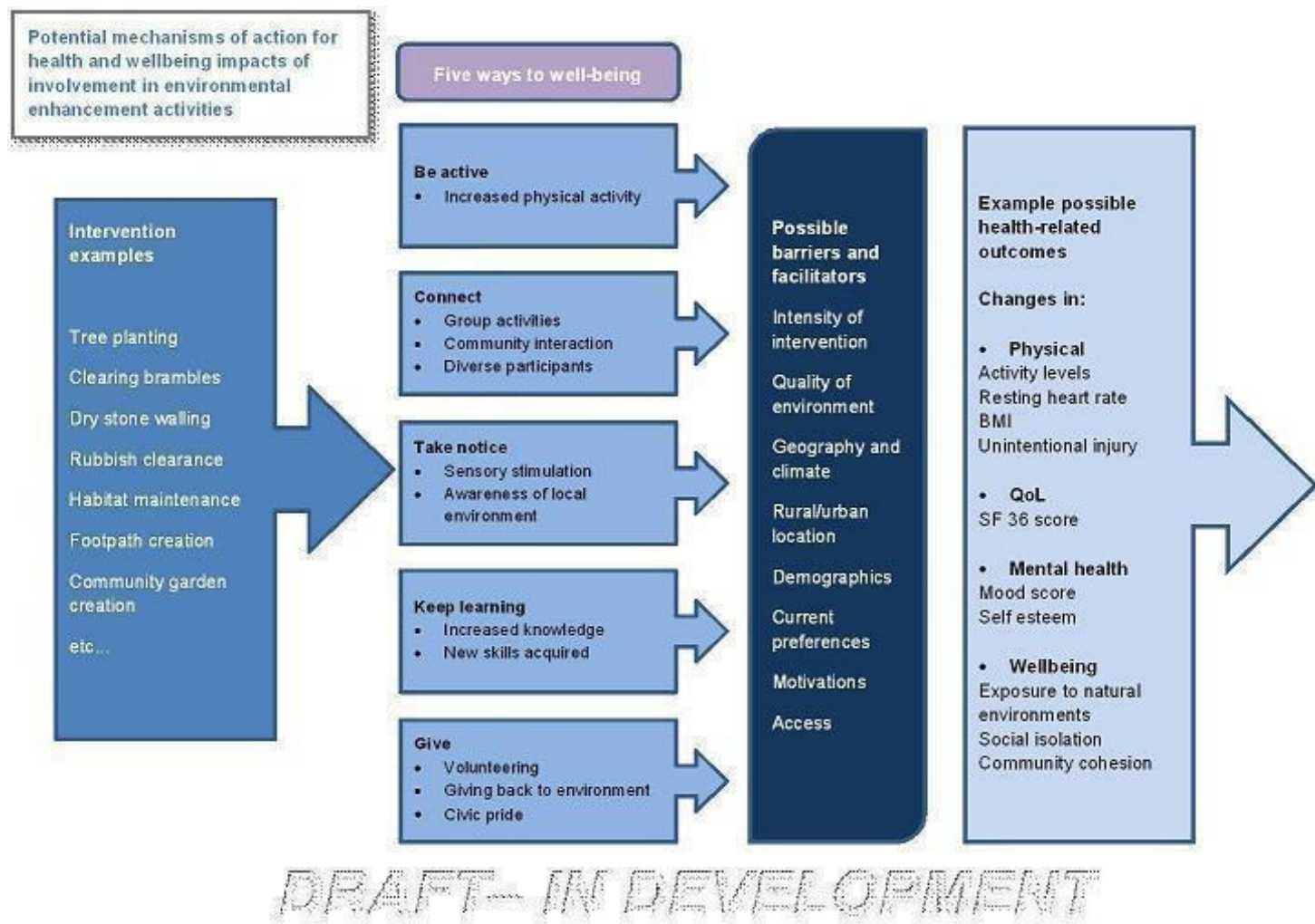

\section{Why it is important to do this review}

Increasingly, public health concern is focused on rising levels of chronic disease, lifestyle conditions such as obesity and heart disease, and mental health conditions such as depression (Maller 2005). Prevention activities and treatments that avoid or reduce pharmaceutical use are appealing in terms of potential benefits to individuals and cost savings to health care systems (Mind 2007). Active use of the outdoor environment as a setting for interventions may be effective at improving mental and physical health indicators. Such activities could have the potential to not only avoid excess pharmaceutical management, improve physical and mental health and well-being, but may also decrease social isolation, improve practical skills, and enhance local environments (Burls 2005). Active engagement with the environment through, for example, environmental enhancement activities is potentially an under-used resource in health promotion and as an intervention for health problems (Maller 2009).

We have been unable to find any reviews which specifically focus on health/well-being outcomes and environmental enhancement activities. The review for NICE cited previously (NICE 2006) included only controlled study designs, specifically focused on enhancement of the natural environment, and only considered increased physical activity as outcomes. Additionally, the review was conducted eight years previous to this protocol and there has been growing research activity in this area since then.

Previous reviews in this field have arguably lacked methodological rigour (Bowler 2009), or focused on a restricted evidence base (NICE 2006). Our approach aims to address these issues. A group of academics has been convened to form an Expert Advisory Group 
to provide methodological input throughout and has commented on drafts of this protocol.

A review currently under consideration with the Cochrane Public Health Group will examine the effects of contact with nature in children. This proposed review by G. Chabot et al. considers parallel, rather than overlapping concerns - the authors plan to look at the health impacts for children of contact with nature more broadly. Our review both takes a different methodological approach, and considers adults engaged specifically in environmental enhancement activities. We hope to keep in touch with the team in Quebec through the course of our review to share insights.

\section{O B J E C T I V E S}

To assess the health and well-being impacts on adults following participation in environmental enhancement and conservation activities.

\section{METHODS}

\section{Criteria for considering studies for this review}

\section{Types of studies}

In the systematic review we will include quantitative studies, including:

- randomised controlled trials (RCTs), cluster RCTs;

- quasi-RCTs, cluster quasi-RCTs;

- controlled before-and-after studies with any appropriate comparator groups;

- interrupted time series;

- cohort studies; and

- case-control study.

Definitions of includable study designs are shown in Appendix 3. For non-randomised studies we will apply minimum criteria for studies to meet for inclusion. Controlled before-and-after studies data collection must be contemporaneous and groups comparable on key characteristics. Interrupted time series studies must clearly define intervention points and record at least three outcome measurement points before and after (or before and during) the intervention. Cohort studies must occur over a reasonable timescale for effects to be detectable and attributable ( $T \geq 6$ months) and accurately record drop-out figures/characteristics. Case-control studies must report cases and controls from studies whose comparability on relevant baseline characteristics and potential confounders can be judged, and comprehensively report confounders.

Also tagged during screening will be uncontrolled before-and-after studies (uBAs). These will be included in the review if no controlled studies are located. Whilst uBAs are prone to higher levels of bias, and are unable to determine causality, in the absence of higher level evidence they are able to demonstrate the settings and contexts of links, as well as key functions and processes in a mapping of the available evidence. A similar approach has been utilised previously in a Cochrane review examining rural hospital settings (Gruen 2004). Qualitative evidence linked to quantitative intervention studies ('sibling studies') will be included. Further qualitative evidence will be identified during the initial screening process, where those studies which appear to be qualitative will be tagged for screening against the qualitative criteria (Harriet 2010; Pearson 2010).

\section{Qualitative Studies}

Included qualitative research will be from any discipline or theoretical tradition that uses recognised qualitative methods of data collection and analysis (Munro 2007). Data collection methods include (but are not limited to): focus groups; individual interviews; ethnographic interviews; participant or systematic observation; documentary analysis; audio visual/note collection. Methods of analyses include: grounded theory; narrative analysis; thematic analysis; hermeneutic phenomenological analysis; discourse analysis.

\section{Types of participants}

Adults (>18) participating in the types of environmental enhancement and conservation activities defined below. Analysis will necessarily be sensitive to potential impacts on specific subgroups; such as those with mental ill health or older people. Socio-economic differences will also be explored.

\section{Types of interventions}

Outdoor, physically active activities involving environmental enhancement and conservation will be included in the review. These activities are those in which participation is intended to improve the natural environment, and can occur in urban or rural areas, built or natural.

In studies where participants engage in a range of activities, and only some participants undertake environmental enhancement, we will include only those studies where data is reported separately for those participating in environmental enhancement. Decisions relating to such studies will be recorded and justified in the report. Studies where participants engage in a mixture of activities (for example, all participate in activities which include urban greening activities but also some art production), will be included when the major activity and focus relates to environmental enhancement. If reported numerically, this will be more than $50 \%$. If not reported numerically, a qualitative judgement will be made by the review team and reasons for including and excluding such studies will be recorded and reported.

Where possible, the impact of different types of programmes (e.g. woodland creation vs. litter picking) and different contexts (e.g. 
urban setting vs. rural or woodland vs. coastal) will be investigated in subgroup analysis.

While in most cases, we anticipate that participation was purely voluntary (e.g. volunteer groups), there are also those for whom participation is non-voluntary or at least represents a constrained choice (such as offender groups, community service activities). Studies which include either voluntary or non-voluntary participation will be included. Studies focusing on adults who undertake environmental enhancement activities as part of formal employment (such as park wardens, tree surgeons) will be excluded. Where studies include both employed and non-employed participation we will extract data referring to only non-employed participants. Where possible we will investigate the impact of different routes to participation in subgroup analysis.

Includable activities which are intended to improve the natural environment are listed below (the list is not exhaustive). The review will not consider studies which focused solely on the benefits to the environment following environmental enhancement activities. The review will consider studies which have focused on the impacts of active participation (both in terms of physical activity and engagement with the enhancement activity), to human health and well-being.

Includable activities:

- litter picking;

- re-greening of built environments;

- tree planting and woodland creation;

- hedge building;

- pathway creation;

- watershed restoration;

- habitat restoration;

- landcare;

- community garden creation (but not use or maintenance);

- forestry or woodland management; or

- decontamination/clearing of communal green space.

In areas which are deemed public or publicly accessible:

- communal green spaces (whether urban or rural);

- communal natural features within public urban built environments;

- public parks;

- community gardens;

- school, hospital or other institutional grounds;

- beaches;

- public footpaths;

- indigenous hunting spaces;

- 'Wilderness' spaces; or

- woodlands and forests.

Activities which are excluded from this review include:

- domestic or allotment gardening;

- therapeutic and care gardening;

- community farming; or

- environmental surveying.
Activities which take place in private environments (e.g. domestic gardening) are excluded. We have excluded activities such as horticultural therapy, community farming and domestic gardening because the aims, motivations and outcomes are likely to differ significantly from those of environmental enhancement (as defined above). We feel that these activities constitute separate reviews and are outside the scope of a single systematic review.

This list is provisional and not exhaustive; other includable activities will be discussed by the team. The Expert Advisory Group (academics) and the Project Reference Group refined the definition of the activities for inclusion (Appendix 1).

Any appropriate comparator activities will be included, for example non-conservation based physical activities, volunteering in non-conservation activities in controlled trials, and cohort measurements in before and after studies.

\section{Types of outcome measures}

\section{Quantitative research}

Outcomes will include any recognised measure of health or wellbeing whether physical or mental (including emotional and quality of life), assessed using self-report or objective measures. Mechanisms known to be determinants of health (i.e. physical activity behaviours) will also be included. Listed in priority order:

1. physiological measures (for example, heart rate, cortisol levels, per cent body fat or BMI);

2. physical health measures, general or specific (for example validated measures such as elements of the Short Form Health Survey or other measures of self-reported health status, measures of general function and capacity);

3. mental and emotional health outcomes (these may include validated scales such as the Warwick-Edinburgh Mental Wellbeing Scale or measures of emotional response, measures of attention restoration/stress recovery); and

4. quality of life measures (e.g. SF-36, EQ-5D).

Additional outcomes, including adverse or unintended outcomes, will be considered where reported alongside health/well-being outcomes:

1. physical activity behaviours (for example, frequency, pattern and intensity of activity, physical activity beliefs and intentions);

2. cognitive performance;

3. rate of recovery from illness or disability (physical or mental);

4. recording of positive feelings, whether the participant enjoyed/liked the experience;

5. data on outcomes related to social cohesion (e.g. UK Citizenship Survey 2009-10 cohesion measures) where reported;

6. measures of increased knowledge about the environment or related educational qualifications gained; and

7. measures of changes in community or volunteering participation.

Participation in environmental enhancement and conservation activities for health and well-being in adults (Protocol) 
Adverse or unintended consequences:

1. injury; and

2. allergenic reaction in response to exposure to environmental triggers (i.e. pollen).

Where data allow, a representative outcome measure for each heading will be selected based on the most frequently reported. For example, scoping and grey literature searches have suggested that heart-rate is the most commonly reported physiological measure, and the short-form SF-36 (SF-12) the most commonly reported QoL measure for environmental enhancement activity.

We will extract data referring to the type, quality and features of the environment in which the activity was undertaken. We will also extract data, where available, referring to the level of participation and exposure to the intervention. For study designs with pre and post measures, time point details will be extracted alongside the outcomes. Where possible, we will collect data on the settings in which the activity takes place for included studies, to provide context for the results.

\section{Qualitative research}

For qualitative studies, findings will relate to the perceived health and well-being impacts, both positive and negative, reported by those participating in environmental enhancement activities. Data in the form of key themes, concepts and metaphors about the impact of participation will be extracted.

\section{Search methods for identification of studies}

Search methods are led by an Information Specialist (CC). Locating evidence for this review will draw upon a variety of search methods, reflecting the diffuse nature of the literature base in this topic, and the difficulties in locating relevant evidence from across the environmental health and conservation fields (Pullin 2001). Given the noted heterogeneity of the literature base (Fazey 2004), with items spread between a variety of mixed topical databases, items which have not been formally published, or not published at all, the review requires an innovative search approach. We will draw upon the standard systematic approaches of electronic bibliographic searching, citation chasing, web-searching, grey-literature searching and expert contact.

\section{Electronic searches}

The bibliographic search syntax was extensively discussed within the review team and further tested before being sent to the convened Project Reference Group for additional comments (Appendix 1). The following databases will be searched:

- Assia (ProQuest);

- BIOSIS (ISI);

- British Education Index (ProQuest);

- British Nursing Index (ProQuest);

- CAB Abstracts (CAB Direct);

- Campbell Collaboration;

- Cochrane Public Health Specialized Register;

- DOPHER (EPPI);

- eMBASE (Ovid);

- ERIC (ProQuest);

- Global Health (Ovid);

- GreenFILE (EBSCO);

- HMIC (Ovid);

- IBSS (ProQuest);

- MEDLINE in Process (Ovid);

- MEDLINE (Ovid);

- OpenGrey;

- PsychINFO (Ovid);

- Social Policy and Practice (Ovid);

- SPORTDiscus ;

- TRoPHI (EPPI);

- Social Services Abstracts (ProQuest);

- Sociological Abstracts (ProQuest);

- The Cochrane Library;

- TRIP Database; and

- Web of Science (including conference citations index) (ISI).

An example of the search strategy illustrating the search terms to be used is available in Appendix 4. Only intervention terms are used in the strategy. The populations included are necessarily broad and terms cannot be included which narrow the field. Similarly, included study designs prevent reduction by comparator group as evidence is likely to exist which has single group samples. Grey literature and scoping searches also highlight the disparity in outcome labelling in this field, which prohibits the inclusion of outcome terms in the strategy.

A year limit has been applied, 1990-current, which is the period in which environmental enhancement activities became widely recognised (the Green Gym project was developed in the late 1990s) and health impact research emerged (see Figure 2).

Participation in environmental enhancement and conservation activities for health and well-being in adults (Protocol) 


\section{Figure 2. Citation report for papers including 'environmental enhancement' in title I 980-20 I 2 (Source: Thomson Reuters 20I2)}

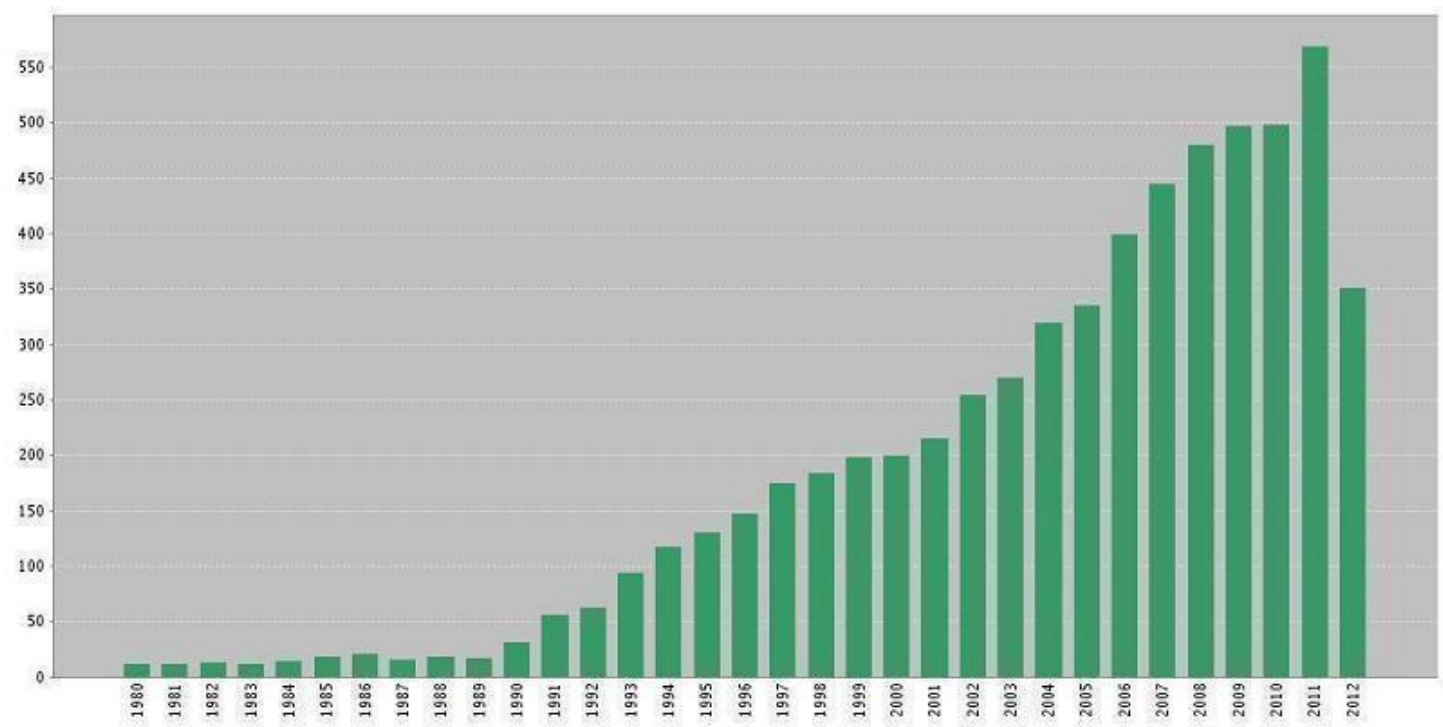

Only papers in English will be included. While we recognise that there is a potential for bias to be introduced as a result, the direction and degree of such bias is unknown. As outlined in the Cochrane Handbook for Systematic Reviews of Interventions (Higgins 2011), there is conflicting evidence about the potential bias introduced by an English language limit: Juni 2002 reported that nonEnglish trials were more likely to report significant results, whilst Moher 2003 reported no significant difference in meta-analyses which excluded trials in languages other than English. Further, such assessments relate to the results of meta-analyses of RCT data which, based on initial scoping searches, are unlikely to form the bulk of evidence in this topic and which, due to the heterogeneity of interventions to be included, is likely to preclude meta-analysis. We anticipate that the synthesis will therefore rely on formal methods of narrative synthesis (Popay 2006). Through the process of the review we will consider the possible impact of the language restriction and will reflect on the limitations in the final report.

Our search for grey literature will unavoidably be mainly focused on UK organisations. The requirement to discuss the project aims with contacts alongside the quantity of organisations in the field could not, realistically, be repeated globally. However we will include evidence from non-UK/European English speaking countries as far as possible. We will ask the Project Reference Group to identify key international organisations and these will also be contacted for relevant unpublished reports. Our website searches (see section below) will include extensive searching of non-UK/ European English speaking countries. The database searches will enable us to identify the implications and limitations of a UK centred grey literature search.

\section{Searching other resources}

Given the difficulties in locating relevant evidence, our bibliographic searching will form one arm of our search strategy for this review. We began with a scoping stage of expert/stakeholder contact searching using web-resources and speaking with organisations of note to identify unique or unpublished items (these organisations can be found in Appendix 5).

We plan to follow with forwards and backwards citation chasing on included items identified above, and 'related article' searches on any items identified.

We shared the initial list of includable studies with the Project Reference Group and known academics in the field to seek further references. We also discussed formal search terms with the Project Reference Group, who will also form a frame of reference for the literature base.

Secondly, and again in development with the Project Reference Group (who will help inform the growth of the list), hand searching will be conducted on the web-sites of the organisations. We recognise that these organisations will have a UK focus and so we will also include non-UK/European English speaking countries, a list of organisations identified can be found in Appendix 6. Sites will be searched using selected terms (see Appendix 6) entered into website search boxes and a manual trawl of the first 100 results. If the first 100 results yield a high level of includable items (i.e. $>10 \%)$ then more hits will be trawled. For websites where searches with a single term result in an excessive number of hits (for ex- 
ample the American EPA), terms will be combined to return only relevant items. Sites where only a small number of publications are listed will be trawled in full. Items will then be downloaded or requested via email.

Grey literature searching will be conducted through bibliographic databases (such as Social Policy and Practice, www.spandp.net), we will also web-search known portals (e.g. Open Grey, www.opengrey.eu) in addition to library catalogues, such as the British Library (www.bl.uk). Google (www.google.com) will also be searched.

As with the citation and related article chasing used in the first step, every includable item will be chased to locate further information. This is important given the variety of places relevant literature is stored.

We will also use citation alerts on included items as there is a delay between acceptance and publication in the conservation literature (Fazey 2004; Kareiva 2002).

\section{Data collection and analysis}

\section{Selection of studies}

Study selection will be in two parts. Firstly, two team members (KH and RL) will independently screen titles, and, where available, abstracts of any identified studies. Where these appear to be relevant given the inclusion criteria detailed, the full text will be obtained and, again, screened by two team members. Where there is disagreement, the researchers will discuss the decision and come to an agreement, or a third researcher (RG) will be brought in to aid consensus.

\section{Data extraction and management}

The exported files from the searching will be uploaded and deduplicated in Endnote 2011. Where an export is not possible, for example from a resource without RIS functionality, the data will be exported to a word file and saved. The searches will be recorded using the Preferred Reporting Items for Systematic Reviews and Meta-Analyses (PRISMA) guidelines (Moher 2009).

Data will be extracted into bespoke data extraction forms developed for the review. Data will be extracted by one reviewer, and checked by another (KH and RL). The final agreed data extraction will be entered into the Cochrane Collaboration's statistical software, Review Manager 2012, by one author (KH). Extracted quantitative data will include: full details of the nature of the intervention (content, time frame of activity and frequency of engagement) and any theory informing it; setting and provider; sample characteristics of the included population; and results of outcomes measured. For included qualitative research, themes, concepts and quotes will be extracted together with details of the sample, methodology and intervention as appropriate.
Equity data will be extracted where study authors have reported on any of the PROGRESS-Plus factors. However variables which impact on participation and outcomes will be prioritised during synthesis: age, gender, race and socio-economic status. The resources and costs of interventions will not be extracted.

\section{Assessment of risk of bias in included studies}

\section{Quantitative studies}

Our study-level appraisal of included randomised studies will utilise the Cochrane Collaboration's tool for assessing risk of bias (Higgins 2011). This two-part tool addresses six domains: sequence generation, allocation concealment, blinding, incomplete outcome data, selective outcome reporting, and other issues. All other quantitative studies will be appraised, where appropriate, based on the Effective Public Health Practice Project (EPHPP) criteria for potential sources of bias (Armijo-Olivo 2012). The EPHPP tool is recommended by the Cochrane Public Health Group as suitable for systematic reviews of effectiveness (Armstrong 2007). The tool assesses studies based on selection bias; study design, confounders, blinding, data collection methods, withdrawals and drop-outs, intervention integrity and analysis. Tools will be piloted on a sub-set of included studies to check criteria application consistency within the team. Each study will be assessed for bias by two reviewers (KH and RL), and disagreements resolved through discussion and, where necessary, a third reviewer (RG).

\section{Qualitative studies}

Qualitative studies will be included in the review to help develop the conceptual framework. Quality of qualitative evidence will be assessed in relation to the "ability and efforts of the researcher to make his or her influence and assumptions clear and to provide accurate information on the extent to which the findings of a research report hold true" (Hannes 2011). We will use the Wallace criteria for appraising each study, to determine quality of reporting and appropriateness of method (Wallace 2004), which we have used in several previous reviews of qualitative research in public health questions (Garside 2010; Smithson 2010). These criteria assess studies based on theoretical perspective; question; study design; context; sampling; data collection; analysis; reflexivity; generalizability; and ethics. Appraisal will be undertaken by two reviewers independently ( $\mathrm{KH}$ and $\mathrm{RL})$, and disagreements resolved through discussion, and a third reviewer (RG) if necessary. All of the tools utilised for assessing risk of bias are detailed in Appendix 7. 


\section{Measures of treatment effect}

We will report continuous data as mean and standard deviation (SD). Where possible, we will use the original scale and standardised mean differences (SMDs) will be calculated where we need to combine data across different scales. Ordinal data, in the form of validated measurement scales, are also likely and, in line with current guidelines by the Cochrane Collaboration, shorter scales will be grouped and analysed as dichotomous outcomes for which we will calculate odds ratios. Longer ordinal scales will treated in analyses as continuous. Counts and rates will be treated as continuous. Based on the activity inclusion criteria and outcome selection, odds ratios (ORs) (rather than risk ratios) will be reported for dichotomous data.

\section{Unit of analysis issues}

Unit of analysis issues relating to repeated observation and event re-occurrence may be present. In these two specific cases, distinct outcomes will be defined and several analyses performed representing each time-frame. Additional care will be taken to include the same group of participants only once in any meta-analyses. Cluster RCTs, whilst unlikely to occur in this review, will be analysed using a summary measurement from each cluster. Multi-arm studies, where available, will be included using group combination to create single pair wise comparisons.

\section{Dealing with missing data}

Missing data will be requested from primary study authors via email. For sets which are missing data meta-analyses will be conducted in accordance with intention to treat analysis. Other analyses will use available data and the final report will reflect this limitation.

\section{Assessment of heterogeneity}

The broad scope of this review means that a wide range of studies will be included and issues of heterogeneity (clinical, methodological and resulting statistical heterogeneity) are increased. Metaanalysis will only be undertaken where there is sufficient homogeneity across participants and outcomes. Meta-analysis may be conducted in this case (in the form of forest plots) where there is limited heterogeneity of intervention to inform broader enhancement activity conclusions.

Chi-squared tests will be used to evaluate heterogeneity, with the appropriate caution of results associated with small-sized studies expected in this case. Inconsistencies in meta-analyses undertaken will be examined using $\mathrm{l}^{2}$, it may be necessary to exclude specific studies.

\section{Assessment of reporting biases}

Environmental enhancement is an emerging field which has been growing in research interest since the 1990s. The nature of the origins of the research (often conducted by environmental enhancement practitioners and those without formal research methods training and not reported through traditional channels) means that reporting biases are likely to be somewhat of an issue in this review. Particularly time-lag, location and multiple publication biases. If data allow meta-analysis to be undertaken we will explore reporting biases through funnel plots. The possible presence and implications of reporting biases will be considered in the report. To counter the introduction of reporting biases three strategies will be used. Firstly, searches include a comprehensive set of databases as identified by the Information Specialist (CC), and the search strategy has been extensively discussed both within and outside the team to be as inclusive as possible. Secondly, grey literature searches and hand-searching of relevant websites will be undertaken by two members of the review team (KH and RL), to identify unpublished reports and items which are location specific. Lastly, the Project Reference Group will be contacted to identify key items in the unpublished literature (Appendix 1).

\section{Data synthesis}

We anticipate that the synthesis will use several tools, depending on the nature of the evidence identified, and in response to the different types of data to be included in the review: these approaches are described in more detail below.

1. Where relevant data are available from trials, it will be meta-analysed to establish pooled effect measures for the stated outcomes.

2. Where data from trials are not available, or where outcomes used or interventions examined are too diverse for sensible pooling, outcomes across studies will be synthesised narratively.

3. Qualitative findings will be initially synthesised separately to provide a comprehensive picture of the themes and concepts available across the studies.

4. An overarching conceptual framework will be used as a mechanism to produce an overarching synthesis of the quantitative qualitative data included in the review. This will illustrate the proposed mechanisms of action, and use data from the studies, and an indication of the strength and quality of the evidence to population this framework.

Initially a conceptual framework will be developed (and later refined throughout the project) to try and understand the proposed modes of action through which it is believed that involvement in environmental enhancement activities produces health and wellbeing effects. This will take the form of both explicit academic theories referenced in project descriptions, as well as implicit 'lay' theories. The framework will both aid evidence identification and help revise the review parameters. It will form a picture of how and why effects occur by positioning theories/mechanisms alongside 
outcomes. The review will populate the links between these areas and an overarching conceptual framework will be a product of the overarching synthesis.

\section{Pooling quantitative evidence: controlled study designs}

Where appropriate trial data are available, random-effects metaanalyses will be undertaken, for which analysis will be performed in Review Manager 2012. uBAs will not be considered for inclusion in this analysis. Experimental and non-experimental data will be synthesised separately, and their impact on an overall pooled effect investigated. Separate synthesis will be conducted, where appropriate, for poorer quality studies to investigate the impact on outcomes and we will conduct a sensitivity analysis to estimate the effect of including or excluding studies with greater risk of bias. Other subgroup analyses will be conducted where data are available relating to: population characteristics (age, gender, race etc), type of involvement and type of activity to explore the possible impact of population and interventions characteristics. Where appropriate we will investigate subgroup heterogeneity through examining the forest plots and the $\mathrm{l}^{2}$ statistic.

Where outcome data are incomplete across the sample, the principles of intention-to-treat analysis (at least available case analysis) will be followed.

A 'Summary of Findings' table will be presented for the outcomes identified, possibly making use of representative outcome measures (Types of outcome measures). The amount and strength of the evidence base for each outcome will be assessed.

\section{Narrative synthesis of quantitative evidence (including uBAs)}

If no, or limited evidence is identified from studies using comparative designs, we will include uBAs in the review. For these uncontrolled before and after studies, and for outcomes from controlled studies where statistical pooling is not possible, or ill advised due to heterogeneity, narrative synthesis methods will be used (Popay 2006). This will include grouping outcomes by type and measure and presenting them in tabulated form, as well as writing a narrative summary of the findings. Where useful, we may convert findings to ORs and SMDs and present them illustratively, without pooling. We will explore similarities and differences in the findings by grouping and juxtaposing them based on: study design; type of participant; type of activity; proposed mechanism of action etc.

\section{Qualitative evidence}

Exact methods of synthesis for the included qualitative research will depend on the nature of the evidence identified. For example, where data are largely descriptive, we will use thematic analysis, whereas more conceptually rich studies may be better suited to a meta-ethnographic approach (Campbell 2003; Garside 2008; Thomas 2008).

\section{Overarching synthesis}

A narrative synthesis of all included evidence will be produced, with particular consideration given to methodological and intervention heterogeneity through the categorisation of studies by their underlying theoretical approaches (both academic and lay theories, including, for example, Wilsons' Biophilia) (Popay 2006). Study-level moderator (and sample characteristic) variables such as study design or population heterogeneity will also be examined to assess the impact on outcomes. Indeed, such contextual factors are central to the review.

We will then use this synthesis to refine the conceptual framework built around proposed mechanisms of health impacts (utilising the best evidence available as described by an evidence hierarchy, including, where appropriate, qualitative studies) (Anderson 2011). In addition, the input of the Project Reference Group will be sought; we have already held our first workshop with this Group and they will continue to be involved through email correspondence and a further workshop planned for the end of 2012. Further details of the conceptual framework can be found in Appendix 2.

\section{Subgroup analysis and investigation of heterogeneity}

The approach taken in this review will examine and try to draw out the interacting effects between mechanisms, outcomes and sub-groups. Interventions will be categorised according to theoretical underpinning (main mechanism of action) consisting of both lay and academic theories. Interventions might also be usefully grouped based on the exposure and type of activity undertaken by participants; there may well be differences between hard physical activities and those with less physical components. Along with participant and intervention characteristics, data will also be analysed using the characteristics of the environment in which the activity was undertaken as a mediating variable.

Analysis will be sensitive to differential impacts by: mental health status; age; socio-economic status; gender and, potentially, ethnicity. Initial exploration of the grey literature and scoping searches indicate that there may be significant potential for levels of health inequality to be perpetuated across those from lower socio-economic backgrounds and those with mental ill health. As such, these two groups will be prioritised in our subgroup analysis.

Where possible, meta-analysis that combine subgroups will be undertaken. These will split participants across the groups mentioned for all outcomes (or summary outcomes for broader headings). However, we anticipate that formal analysis is unlikely to be possible and so observational differences will be explored comprehensively through modelling the subgroup interacting effects on the conceptual framework.

\section{ACKNOWLEDGEMENTS}


We would like to thank the editors of the Cochrane Public Health Group and the topic referees for their helpful comments on earlier drafts of this protocol. The systematic review for which this protocol has been developed is funded by the NIHR School for Public Health Research (SPHR). The views expressed in this publication are those of the authors and not necessarily those of the National Health Service, NIHR or the Department of Health.

\section{R E F E R E N C E S}

\section{Additional references}

\section{Anderson 2011}

Anderson L M, Petticrew M, Rehfuess E, Armstrong R, Ueffing E, Baker P, et al.Using logic models to capture complexity in systematic reviews. Research Synthesis Methods 2011;2:33-42.

Armijo-Olivo 2012

Armijo-Olivo S, Stiles CR, Hagen NA, Biondo PD, Cummings GG. Assessment of study quality for systematic reviews: a comparison of the Cochrane Collaboration Risk of Bias Tool and the Effective Public Health Practice Project Quality Assessment tool: methodological research. Journal of Evaluation in Clinical Practice 2012;18(1):12-8.

Armstrong 2007

Armstrong R, Waters E, Jackson N, Oliver S, Popay J, Shepherd J, et al.Guidelines for Systematic reviews of health promotion and public health interventions. Version 2. Australia: Melbourne University, 2007.

Beatley 2011

Beatley T. Biophilic cities: integrating nature into urban design and planning. Washington: Island Press, 2011.

Bize 2007

Bize R, Johnson JA, Plotnikoff RC. Physical activity level and health-related quality of life in the general adult population: a systematic review. Preventitive Medicine 2007; 45(6):401-15.

Bowler 2009

Bowler D, Knight T, Pullin A S. The value of contact with nature for health promotion: how the evidence has been reviewed. Centre for Evidence-Based Conservation, 2009.

Burls 2005

Burls A, Caan W. Human health and nature conservation - ecotherapy could be beneficial, but we need more robust evidence.. British Medical Journal 2005;331:1221-2.

Burls 2007

Burls A. People and green spaces: promoting public health and mental well-being through ecotherapy. Journal of Public Mental Health 2007;6:24-9.

Bushway 2011

Bushway J, Dickinson L, Stedman C, Wagenet P, Weinstein A. Benefits, motivations, and barriers related to environmental volunteerism for older adults: developing a research agenda. International Journal of Aging and Human Development 2011;72(3):189-206.

\section{Campbell 2003}

Campbell R, Pound P, Pope C, Britten N, Pill R, Morgan $M$, et al.Evaluating meta-ethnography: a synthesis of qualitative research on lay experiences of diabetes and diabetes care. Social Science and Medicine 2003;56:671-84.

\section{Defra 2011}

Defra HMG. The natural Choice: securing the value of nature. Norwich: The stationary office, 2011.

Endnote 2011

Thomson Reuters. Endnote. X5. New York: Thomson Reuters, 2011.

\section{Evans 2008}

Evans M, Gebbels S, Stockill M. 'Our shared responsibility': participation in ecological projects as a means of empowering communities to contribute to coastal management processes. Marine Pollution Bulletin 2008;57:3-7.

Fazey 2004

Fazey I, Salisbury J, Lindenmayer D, Maindonald J, Douglas R. Can methods applied in medicine be used to summarize and disseminate conservation research?. Environmental Conservation 2004;31:190-8.

Fieldhouse 2003

Fieldhouse, J. The impact of an allotment group on mental health client's wealth, well-being and social networking. British Journal of Occupational Therapy 2003;66:286-296.

\section{Fjortoft 2001}

Fjortoft I. The natural environment as a playground for children: the impact of outdoor play activities in preprimary school Children. Early Childhood Education Journal 2001;29(2):111-7.

\section{Garside 2008}

Garside R, Britten N, Stein K. The experience of heavy menstrual bleeding: A systematic review and metaethnography of qualitative studies. Journal of Advanced Nursing 2008;63:550-62.

\section{Garside 2010}

Garside R, Pearson M, Moxham T. What influences the uptake of information to prevent skin cancer? A systematic review and synthesis of qualitative research. Health Education Research 2010;25(1):162-82. 
Gruen 2004

Gruen RL, Weeramanthri TS, Knight SE, Bailie RS. Specialist outreach clinics in primary care and rural hospital settings. Cochrane Database of Systematic Reviews 2003, Issue 4. [DOI: 10.1002/14651858.CD003798.pub2]

Hale 2011

Hale J, Knapp C, Bardwell L, Buchenau M, Marshall J, Sancar F, et al.Connecting food environments and health through the relational nature of aesthetics: gaining insight through the community gardening experience. Social Science and Medicine 2011;72(11):1853-63.

Hannes 2011

Hannes K. Chapter 4: Critical appraisal of qualitative research. In: Noyes J, Booth A, Hannes K, Harden A, Harris J, Lewin S, Lockwood C editor(s). Supplementary Guidance for Inclusion of Qualitative Research in Cochrane Systematic Reviews of Interventions. Version 1 (updated August 2011). Bangor: Cochrane Collaboration Qualitative Methods Group, 2011.

\section{Harriet 2010}

Harriet H, Anderson R, Coelho HF, Garside R, Bayliss $S$, Fry-Smith A. Preventing obesity: the effectiveness of a whole system approach. http://www.nice.org.uk/nicemedia/ live/12109/55099/55099.pdf (accessed 02082012).

\section{Haubenhofer 2010}

Haubenhofer D, Elings M, Hassink J, Hine R. The development of green care in western European countries. Explore: The Journal of Science and Healing 2010;6(2): 106-11.

\section{Hermann 2006}

Hermann JR, Parker SP, Brown BJ, Siewe YJ, Denney BA, Walker SJ. After-school gardening improves children's reported vegetable intake and physical activity. Journal of Nutrition Education and Behavior 2006;38:201-2.

\section{Herzele 2012}

Herzele A, Vries S. Linking green space to health: a comparative study of two urban neighbourhoods in Ghent, Belgium. Population and Environment 2012;34(2):171-93.

\section{Higgins 2011}

Higgins JPT, Green S (editors). Cochrane Handbook for Systematic Reviews of Interventions Version 5.1.0 [updated March 2011]. The Cochrane Collaboration, 2011. Available from www.cochrane-handbook.org.

Horwitz 2012

Horwitz P, Finlayson M, Weinstein P. Healthy wetlands, healthy people: a review of wetlands and human health interactions. Ramsar Technical Report No. 6. Secretariat of the Ramsar Convention on Wetlands, Gland, Switzerland, $\&$ the The World Health Organisation, Geneva, Switzerland 2012.

Joye 2011

Joye Y, De Block A. 'Nature and I are two': a critical examination of the Biophilia Hypothesis. Environmental Values 2011;20(2):189-215.
Juni 2002

Jüni P, Holenstein F, Sterne J, Bartlett C, Egger M.

Direction and impact of language bias in meta-analyses of controlled trials: empirical study. International Journal of Epidemiology 2002;31:115-23.

Kaplan 1989

Kaplan R, Kaplan S. The Experience of Nature: A Psychological Perspective. Cambridge: Cambridge University Press, 1989.

Kareiva 2002

Kareiva P, Marvier M, West S, Hornisher J. Slow-moving journals hinder conservation efforts. Nature 2002;420 (6911):15.

Lee 2011

Lee ACK, Maheswaran R. The health benefits of urban green spaces: a review of the evidence. Journal of Public Health 2011;33(2):212-22.

\section{Maas 2008}

Maas J, Verheij R, Spreeuwenberg P, Groenewegen P. Physical activity as a possible mechanism behind the relationship between green space and health: a multilevel analysis. BMC Public Health 2008;8:206.

\section{Maller 2005}

Maller C, Townsend M, Pryor A, Brown P, St Leger L. Healthy nature healthy people: "contact with nature" as an upstream health promotion intervention for populations. Health Promotion International 2005;21:45-54.

\section{Maller 2009}

Maller C, Henderson-Wilson C, Townsend M.

Rediscovering nature in everyday settings: or how to create healthy environments and healthy people. Ecohealth 2009;6 (4):553-6.

\section{Mind 2007}

Mind. Ecotherapy - the agenda for green mental health. Mind 2007.

\section{Moher 2003}

Moher D, Pham B, Lawson ML, Klassen TP. The inclusion of reports of randomised trials published in languages other than English in systematic reviews. Health Technology Assessment 2003;7:1-90.

\section{Moher 2009}

Moher D, Liberati A, Tetzlaff J, Altman DG, PRISMA Group. Preferred reporting items for systematic reviews and meta-analyses: the PRISMA Statement. PLoS Medicine 2009;6(7):e1000097.

Moore 2006

Moore M, Townsend M, Oldroyd J. Linking human and ecosystem health: The benefits of community involvement in conservation groups. Ecohealth 2006;3(4):255-61.

Morris 2003

Morris N. Health Wellbeing and Open Space: Literature review. Edinburgh: Edinburgh College of Art and HerriotWatt University, 2003.

\section{Munro 2007}

Munro SA, Lewin SA, Smith HJ, Engel ME, Fretheim A, Volmink J. Adherence to tuberculosis treatment: a 
qualitative systematic review of stakeholder perceptions. PLoS Medicine 2007;4(7):e238.

\section{Musick 2003}

Musick MA, Wilson J. Volunteering and depression: the role of psychological and social resources in different age groups. Social Science and Medicine 2003;56(2):259-69.

\section{NEF 2011}

NEF. Five Ways to Wellbeing. New applications, new ways of thinking. London: New Economic Foundation, 2011.

\section{NICE 2006}

NICE. Physical activity and the environment: Review Three: Natural Environment In NICE Public Health Collaborating Centre - Physical Activity. London: NICE, 2006.

\section{NICE 2009}

NICE. Methods for the development of NICE public health guidance (second edition). London: NICE, 2009.

\section{O'Brien 2010}

O'Brien L, Townsend M, Ebden M. 'Doing something positive': volunteers' experiences of the well-being benefits derived from practical conservation activities in nature. Voluntas 2010;21(4):525-45.

\section{O'Brien 2011}

O’Brien L, Burls A, Townsend M, Ebden M. Volunteering in nature as a way of enabling people to reintegrate into society. Perspectives in Public Health 2011;131:71-81.

Patz 2012

Patz J, Corvalan C, Horwitz P, Campbell-Lendrum D. Our Planet, Our Health, Our Future. Human health and the Rio Conventions: biological diversity, climate change and desertification. A discussion paper, based on a collaboration of the World Health Organization and the Secretariats of the Convention on Biological Diversity, the United Nations Framework Convention on Climate Change and the United Nations Convention to combat desertification. http://www.who.int/globalchange/publications/reports/ healthintherioconventions/en/index.html (accessed 09122012).

\section{Peacock 2007}

Peacock J, Hine R, Pretty J. Got the blues, then find some greenspace. The mental health benefits of green exercise activities and green care. London: Mind, 2007.

Pearson 2010

Pearson M, Garside R, Fry-Smith A, Bayliss S, Anderson R. Preventing obesity using a whole system approach at the local level: A systematic review of the qualitative research to identify barriers to and facilitators of effective whole system approaches. http://www.nice.org.uk/nicemedia/live/12109/ 55101/55101.pdf (accessed 02082012).

\section{Pillemer 2010}

Pillemer K, Fuller-Rowell T, Reid M, Wells N.

Environmental volunteering and health outcomes over a 20 year period. Gerontologist 2010;50:594-602.

\section{Plante 2007}

Plante T, Gores C, Brecht C, Caroow J, Imbs A, Willemsen E. Does exercise environment enhance the psychological benefits of exercise for women?. International Journal of

Stress Management 2007;14(1):88-98.

Popay 2006

Popay J, Roberts H, Sowden AJ, Petticrew M, Arai L, Rodgers $\mathrm{M}$, et al.Guidance on the conduct of narrative synthesis in systematic reviews. Vol. 1, London: ESRC Methods Programme, 2006.

Pretty 2007

Pretty J, Peacock J, Hine R, Sellens M, South N, Griffin M. Green exercise in the UK countryside: Effects on health and psychological well-being, and implications for policy and planning. Journal of Environmental Planning and Management 2007;50(2):211-31.

\section{Pullin 2001}

Pullin A, Knight T. Effectiveness in conservation practice: pointers from medicine and public health. Conservation Biology 2001;15(1):50-4.

\section{Raske 2010}

Raske M. Nursing home quality of life: study of an enabling garden. Journal of Gerontological Social Work 2010;53(4): 336-51.

\section{Review Manager 2012}

The Nordic Cochrane Centre, The Cochrane Collaboration. Review Manager (RevMan). 5.2. Copenhagen: The Nordic Cochrane Centre, The Cochrane Collaboration, 2012.

\section{RSPB 2004}

Royal Society for the Protection of Birds. Natural fit: can green space and biodiversity increase levels of physical activity? RSPB, 2004.

Sempik 2010

Sempik J, Hine R, Wilcox D (eds). Green Care: A conceptual framework. A report of the working group on health benefits of green care. Loughborough: Centre for Child and family Research, Loughborough University, 2010.

\section{Smithson 2010}

Smithson J, Garside R, Pearson M. Barriers to, and facilitators of the prevention of unintentional injury in children in the home: a systematic review and synthesis of qualitative research. Injury Prevention 2010;17:119-26.

Thomas 2008

Thomas J, Harden A. Methods for the thematic synthesis of qualitative research in systematic reviews. BMC Medical Research Methodology 2008;8:45.

Thompson Coon 2011

Thompson Coon J, Boddy K, Stein K, Whear R, Barton J, Depledge MH. Does participating in physical activity in outdoor natural environments have a greater effect on physical and mental well-being than physical activity indoors? A systematic review. Environmental Science and Technology 2011;45:1761-72.

Thomson Reuters 2012

Thomson Reuters Web of Knowledge. Citation report: environmental enhancement. http:// apps.webofknowledge.com (accessed 15082012). 
Townsend 2006

Townsend M. Feel blue? Touch green! Participation in

forest/woodland management as a treatment for depression.

Urban Forestry and Urban Greening 2006;5(3):111-20.

Ulrich 1991

Ulrich R, Simonst R, Lositot B, Fioritot E, Milest M,

Zelsont M. Stress recovery during exposure to natural and urban environments. Journal of Experimental Psychology 1991;11:201-30.

Wallace 2004

Wallace A, Croucher K, Quilagars D, Baldwin S. Meeting the challenge: developing systematic reviewing in social policy. Poicy and Politics 2004;32(4):455-70.

Wilson 1984

Wilson E O. Biophilia. Cambridge: Harvard University

Press, 1984.

* Indicates the major publication for the study

\section{A P P E N DICES}

\section{Appendix I. Expert Advisory Group and Project Reference Group}

An Expert Advisory Group has been convened and whose primary role will be to act as "critical friends" for the review methods. Each brings distinct expertise to the project.

A Project Reference Group has been convened in an advisory capacity, and is comprised of workers and participants in environmental enhancement and conservation activities. Included are representatives from a wide range of key organisations such as the Conservation Volunteers, Mind, Local Authorities, and Green-space. The list was populated through direct author contacts, web searches, and snowball contacting. Due to the necessity of a physical meeting the participants are representatives from UK-based national and local organisations.

The group contributed to:

- Sharing knowledge of organisations involved in relevant schemes and the nature of these activities;

- Ensuring we had a comprehensive picture of the research and evaluations that have been undertaken in this area (especially the grey literature); and

- Ensuring that we are appropriately conceiving that anticipated benefit for participation across difference groups and how these are achieved (programme theories).

The Project Reference Group was convened at an initial meeting, which explained the purpose and scope of the project. The practical and theoretical experience of the group informed the initial conceptual framework which outlines the mechanisms through which involvement in these activities is thought to impact on physical and mental health and well-being. The framework will also allow us to draw out expected similarities and differences between settings, activities and participants. The conceptual framework will necessarily evolve throughout the review and thus the Project Reference Group input will continue. A second meeting will be held towards the end of the project, during which the initial findings, and the conceptual framework will be presented to the group, and opportunities for dissemination discussed.

Participation in environmental enhancement and conservation activities for health and well-being in adults (Protocol) 


\title{
Appendix 2. Conceptual framework
}

An initial conceptual framework, which has been developed through a reading of the literature and consultations with the Project Reference Group, outlines the way in which participation in environmental enhancement and conservation activities is believed to impact on physical, mental, social and emotional well-being. The review will focus on identifying research in key areas of this framework to establish the amount and strength of evidence to support the proposed links.

The further developed framework will be circulated, on at least one occasion, amongst the expert advisory group of academics and the Project Reference Group.

\section{Appendix 3. Definitions of study designs}

\section{Randomised controlled trial (RCT)}

A trial where participants (or clusters) are randomly allocated to receive either intervention or control. If well implemented, randomisation should ensure that intervention and control groups only differ in their exposure to treatment.

Cluster randomised controlled trial

A trial where the unit of randomisation is a cluster of participants (for example, a school). See randomised controlled trial (RCT).

Controlled before-and-after (CBA) study

A trial where participants (or clusters) are allocated to receive either intervention or control (or comparison intervention) but the allocation is not randomised.

\section{Interrupted time series}

An approach in which multiple (more than two) observations are made on the same individuals, or groups of individuals, over time. Cohort studies

An observational study in which a group or 'cohort' of people are observed over time in order to see who develops the outcome of interest. An approach that is often called a longitudinal study. Cohort studies differ from experimental studies such as randomised or non-randomised controlled trials because individuals effectively allocate themselves according to the extent of their exposure to the risk factor of interest. Prospective cohort studies involve following groups of people forward in time to assess who develops the outcome of interest, often by conducting a series of cross-sectional studies. Conversely, in retrospective cohort studies, both the exposure and outcomes of interest all take place in the past relative to the starting point of the study.

Case-control studies

A comparative observational study in which the investigator selects people who have an outcome of interest (for example, developed a disease) and others who have not (controls), and then collects data to determine previous exposure to possible causes. Case-control studies are often reserved for early hypothesis testing or for investigating the causes of rare outcomes.

(Uncontrolled) Before-and-after studies

An approach where the dependent variables are measured before and after an intervention has been delivered. The intervention can either be delivered by the investigator or by others (observational before and after study). An approach that is often called a pre-post study. Study participants in pre- and post-intervention stages can either be the same (A) - as is often the case for simple one-to-one intervention studies - or different (B) - as is often the case for assessing large scale interventions.

Derived from NICE 2009

\section{Appendix 4. Search syntax}

\author{
Database(s): Ovid MEDLINE(R) \\ Host: OVID \\ Data Parameters: 1946 to September Week 32012 \\ Date Searched: Wednesday October $3^{\text {rd }} 2012$ \\ Searched By: CC \\ Strategy Checked by: KH, RL and RG
}

\section{Search Strategy}




\begin{tabular}{l|l|l}
\hline \# & Searches & Results \\
\hline 1 & $\begin{array}{l}\text { (conservation \$ and natural and environment\$ and (renewal or } \\
\text { volunteer\$ or voluntary or participat\$ or practical or regenerat\$ } \\
\text { or restor\$ or maintain\$ or care or enhance\$ or preserve or creat\$ } \\
\text { or activ\$ or action\$ or involve\$)).ti,ab }\end{array}$ & 377 \\
\hline 2 & $\begin{array}{l}\text { (Conservation adj3 interventions).ti,ab. } \\
\text { ((environmental\$ adj3 (conservation\$ or volunteer\$ or stew- }\end{array}$ & 73 \\
\hline 3 & $\begin{array}{l}\text { ard\$) and (Regenerat\$ or restore or restoration or redevelop } \\
\text { or maintain or enhance or preserve or preserving or create or } \\
\text { creation or establish or establishing or founding or build\$ or } \\
\text { cultivat } \$ \text { or cultivation or participate or participation)).ti,ab }\end{array}$ & \\
\hline
\end{tabular}

4 (conservation\$ adj3 (group\$ or volunteer\$ or voluntary or as- 747 sociation $\$$ or organisation $\$$ or organization $\$$ or participa $\$$ or stakeholder $\$$ or steward $\$$ or trust or ranger $\$$ or activit $\$)$ ).ti,ab

5 (conservation \$ adj5 (nature or rural or countryside or outdoor\$ or outside or backcountry or hinterland or outback or wood\$ or park\$1 or parkland or garden\$ or meadow\$ or farm $\$$ or (farm adj1 land) or horticultural or floricultural or botanical or arboretum or allotment $\$$ or forest $\$$ or rainforest or moor\$ or dale $\$ 1$ or marsh $\$$ or mountain $\$$ or beach $\$$ or wilderness or landscape $\$$ or tree $\$$ or copse $\$$ or river $\$$ or lake $\$$ or canal $\$$ or waterway or wetland $\$$ or (open adj1 space $\$$ ) or (protected adj1 area $\$$ ) or green $\$$ or planning $\$$ or footpath $\$$ or trail $\$$ or coast $\$$ or cliff\$ or dune\$ or (bio adj1 diversity) or (eco adj1 system) or (protected adj1 area $\$))$ ).ti,ab

6 (geoconservation or (geo adj3 conservation)).ti,ab.

0

7 ((activ\$ or practical or participat\$) adj3 conservation\$).ti,ab 481

8 exp "Conservation of Natural Resources"/ or *Environment/ 42248 or *Environment Design/

9 (volunteer\$ or voluntary).ti,ab. or *Voluntary Workers/ or 199928

${ }^{*}$ Consumer Participation/ or *Health Status/

$\begin{array}{lll}10 & 8 \text { and } 9 & 638\end{array}$

111 or 2 or 3 or 4 or 5 or 6 or 7 or 10

12 ((Volunteer\$ or voluntary) adj5 (environment\$ or nature or 1142 rural or countryside or outdoor $\$$ or outside or backcountry or hinterland or outback or wood $\$$ or park $\$ 1$ or parkland or garden $\$$ or meadow\$ or horticultural or floricultural or botanical 
or arboretum or allotment $\$$ or forest $\$$ or rainforest or moor\$ or dale $\$ 1$ or marsh $\$$ or mountain $\$$ or beach $\$$ or wilderness or landscape $\$$ or tree $\$$ or copse $\$$ or river $\$$ or lake $\$$ or canal $\$$ or waterway or wetland $\$$ or (open adj1 space $\$$ ) or (protected adj1 area $\$$ ) or green $\$$ or planning $\$$ or footpath $\$$ or trail\$ or coast $\$$ or cliff $\$$ or dune $\$$ or (bio adj1 diversity) or (eco adj1 system) or (protected adj1 area\$))).ti,ab

13 (((voluntary or volunteer\$) adj5 (group\$ or association or stakeholder\$ or steward\$ or ranger\$)) and (environment $\$$ or nature or rural or countryside or outdoor $\$$ or outside or backcountry or hinterland or outback or wood $\$$ or park $\$ 1$ or parkland or garden $\$$ or meadow\$ or horticultural or floricultural or botanical or arboretum or allotment $\$$ or forest $\$$ or rainforest or moor $\$$ or dale $\$ 1$ or marsh $\$$ or mountain $\$$ or beach $\$$ or wilderness or landscape $\$$ or tree $\$$ or copse $\$$ or river $\$$ or lake $\$$ or canal\$ or waterway or wetland\$ or (open adj1 space\$) or (protected adj1 area $\$$ ) or green $\$$ or planning $\$$ or footpath\$ or trail $\$$ or coast $\$$ or cliff $\$$ or dune $\$$ or (bio adj1 diversity) or (eco adj1 system) or (protected adj1 area $\$))) . t i, a b$

15 (environment\$ or nature or rural or countryside or outdoor\$ or outside or backcountry or hinterland or outback or wood $\$$ or park $\$ 1$ or parkland or garden $\$$ or meadow $\$$ or horticultural or floricultural or botanical or arboretum or allotment $\$$ or forest $\$$ or rainforest or moor $\$$ or dale $\$ 1$ or marsh $\$$ or mountain $\$$ or beach $\$$ or wilderness or landscape $\$$ or tree $\$$ or copse $\$$ or river\$ or lake\$ or canal\$ or waterway or wetland\$ or (open adj1 space\$) or (protected adj1 area $\$$ ) or green $\$$ or planning $\$$ or footpath $\$$ or trail $\$$ or coast $\$$ or cliff $\$$ or dune $\$$ or (bio adj1 diversity) or (eco adj1 system) or (protected adj1 area $\$$ )).ti,ab

$\begin{array}{lll}16 & 14 \text { and } 15 & 356\end{array}$

$\begin{array}{lll}1712 \text { or } 13 \text { or } 16 & 2010\end{array}$

18 (Green\$ adj3 (space\$ or gym or exercise or volunteer\$ or vol- 402 untary or conservation or infrastructure or care or streets or communal or Guerrilla)).ti,ab

19 greenspace.ti,ab.

21 (urban adj3 (green $\$$ or park $\$ 1$ or parkland or garden $\$$ or hor- 579 ticultur $\$$ or wood $\$$ or forest $\$$ or botanical or arboretum or allotment\$ or (open adj1 space))).ti,ab 
22 ( (work\$ or renewal or volunteer\$ or voluntary or practical or regenerat $\$$ or restor $\$$ or maintain $\$$ or care or enhance or preserve or creat\$) and (urban or city or metropolis or town\$) and (garden\$ or park\$1 or parkland or allotment $\$$ )).ti,ab

$23{ }^{*}$ Cities/ and ((work\$ or renewal or volunteer\$ or voluntary or 5 practical or regenerat\$ or restor\$ or maintain $\$$ or care or enhance or preserve or creat $\$$ ) and (garden $\$$ or park $\$ 1$ or parkland or allotment\$)).ti,ab

$24{ }^{*}$ Urban Health/ and (*Conservation of Natural Resources/ or 19 *Voluntary Workers/)

26 ( garden $\$$ or horticulture or allotment $\$$ or botanical or arboretum) adj5 (kitchen or school\$ or college $\$$ or university or campus or hospital\$ or prison $\$$ or penitentiary or institution or urban or green $\$$ or communit\$ or communal or group\$ or guerrilla or (bio adj1 diver\$) or eco or ((grow or pick) adj3 your own))).ti,ab

27 ( garden $\$$ or horticulture or allotment $\$$ or botanical or arboretum) adj5 (maintain $\$$ or creat $\$$ or culivat $\$$ or enhance $\$$ or preserve or voluntary or volunteer or conservation $\$$ or participat\$) ).ti,ab

28 Gardening/ and (*Conservation of Natural Resources/ or *Voluntary Workers/)

$29{ }^{*}$ Gardening/ and (kitchen or school\$ or college $\$$ or university or campus or hospital\$ or prison $\$$ or penitentiary or institution or urban or green $\$$ or communit $\$$ or communal or group\$ or guerrilla or (bio adj1 diver\$) or eco or maintain $\$$ or creat $\$$ or culivat $\$$ or voluntary or volunteer or conservation $\$$ or participat\$).ti,ab

31 (communit\$ adj5 (group\$ or team\$ or association\$ or organisation or organization or participa $\$$ or stakeholder $\$$ or steward $\$$ or trust $\$$ or ranger\$ or activit\$)) and (garden\$ or allotment\$ or forest or (natural and environment) or conservation\$)).ti,ab

32 (communit\$ and (work\$ or renewal or volunteer\$ or voluntary or practical or regenerat $\$$ or restor $\$$ or maintain $\$$ or care or enhance $\$$ or preserve or creat $\$$ or activ $\$$ or action $\$$ or involve\$) and ((natur\$ adj3 environment\$) or (environmental\$ and conservation\$)) $)$.ti,ab 
33 (( (communit\$ or local) adj5 (garden $\$$ or park\$ or green $\$$ or greenspace or outdoor $\$$ or outside $\$$ or pavement $\$$ or sidewalk\$ or wood $\$$ or allotment $\$$ or lake $\$$ or canal $\$$ or river $\$)$ ) and (work\$ or renewal or volunteer\$ or voluntary or practical or participat $\$$ or regenerat $\$$ or restor $\$$ or maintain $\$$ or enhance or preserve or creat $\$)$ ).ti,ab
813

1556

8554

3785951

$37 \quad 35$ not $36 \quad 6941$

38 (clinical or surgery or surgical or cell or cells or laboratory or 9317419 placebo or bladder or uterus or breast or gene or genes or genetic or bowel or liver or enzymes or viral or lymph or molecular). $\mathrm{mp}$

3937 not 38

40 limit 39 to english language 4349

41 limit 40 to $\mathrm{yr}=$ "1990 -Current" 3896

Hits: 3896

Notes: N/A

File Saved: Medline Endnote RIS 3896.txt

Appendix 5. List of organisations contacted

\begin{tabular}{|c|c|}
\hline The Conservation Volunteers (BTCV) & Hush Farms \\
\hline 2020 Vision & Isle of Anglesey County Council \\
\hline Aaron Pyecroft & Isle of Wight AONB \\
\hline Active Wales & Isles of Scilly AONB \\
\hline Age UK & Keep Britain Tidy, Beach Care \\
\hline Ambios & Keep Wales Tidy \\
\hline Arnside and Silverdale AONB & Kent Downs AONB \\
\hline
\end{tabular}


(Continued)

\begin{tabular}{|c|c|}
\hline Avon Wildlife Trust & Kent High Weald Partners \\
\hline Bailies of Bennachie & Kent nat tr vol \\
\hline Basingstoke con vol & LANTRA \\
\hline BeachCare (Keep Britain Tidy) & Lea Bridge con vol \\
\hline Berkshire con vol & LEAF/Let nature feed your senses \\
\hline B'ham Guild (Broader) & Leicester con vol \\
\hline Biodiversity SW & Lincolnshire Wolds AONB \\
\hline Biosphere CLS & Liverpool PCT \\
\hline Birmingham Guild for Student Colunteers & Llyn Peninsula AONB \\
\hline Blackdown Hills AONB & London and w/msex vol \\
\hline Blackdown Hills Hedge Association & Lothian con vol \\
\hline Blackwater Valley countryside volunteers & Love where you live \\
\hline Bolton conservation vol & Malvern Hills AONB \\
\hline Bolton Wildlife Programme & Manchester nat tr vol \\
\hline Bournemouth nat tr vol & Marine Conservation Society \\
\hline Bracknell con vol & Medway Valley Countryside Partnership \\
\hline British Waterways & Mendip Hills AONB \\
\hline BVSC (Birmingham) & MIND (Eco Minds) \\
\hline Cambridge con vol & $\mathrm{MoD}$ \\
\hline Camp Kernow & Moor Trees \\
\hline Cannock Chase AONB & NAAONB \\
\hline Canterbury Environmental Education Centre & Nat Eng Big Lottery projs \\
\hline Cardiff con vol & National Parks \\
\hline Carymoor Env trust & National Trust \\
\hline
\end{tabular}


(Continued)

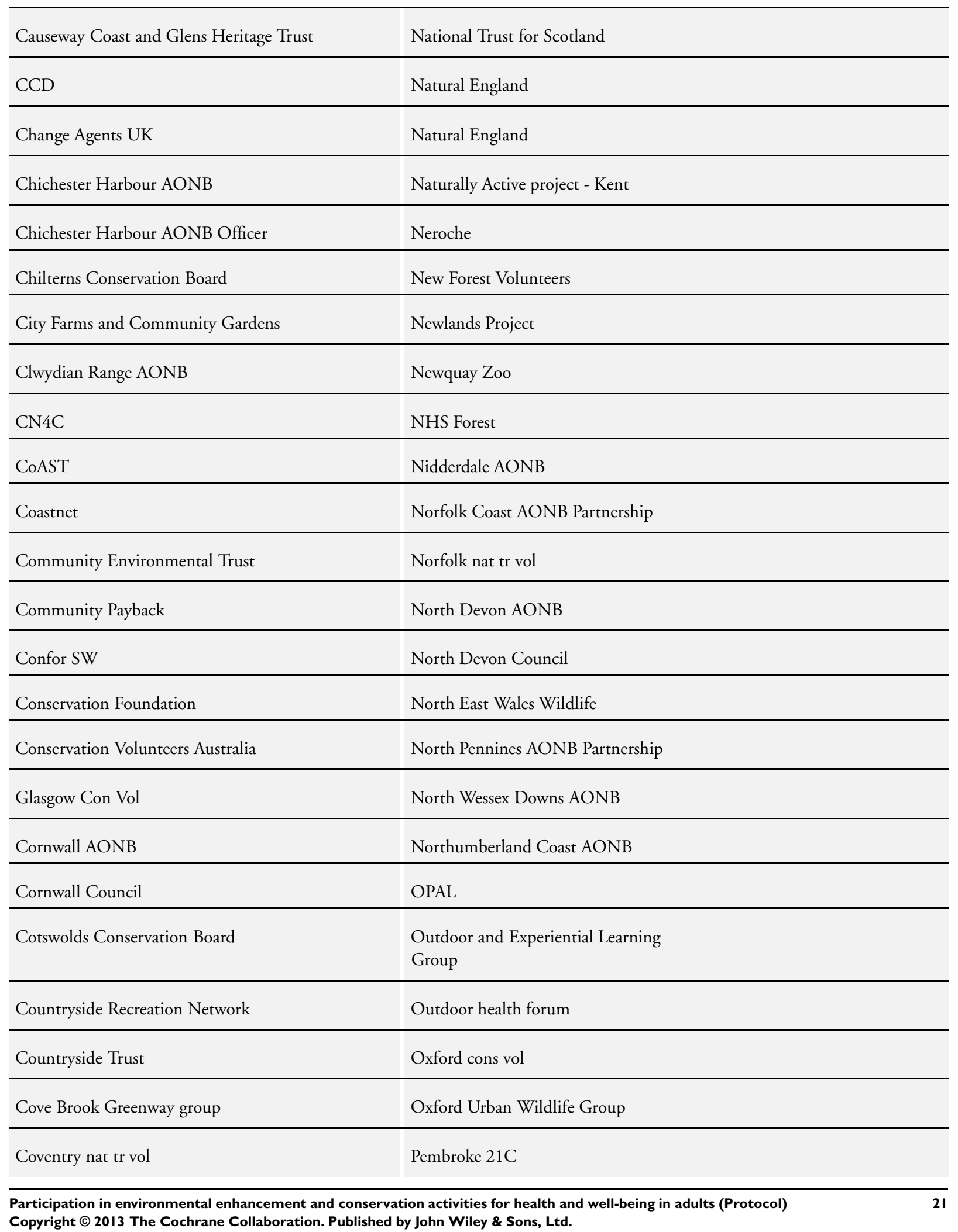


(Continued)

\begin{tabular}{|c|c|}
\hline CPRE & People and Planet \\
\hline Cranborne Chase and West Wiltshire Downs AONB & Plantlife International \\
\hline CRCC & Plymouth Environmental Action \\
\hline CRESH & Plymouth Student Scientist \\
\hline CSV & PROSPECTS \\
\hline Cusgarne Organic Farm & Quantock Hills AONB \\
\hline CVS & Reforesting Scotland \\
\hline Dartmoor Preservation Association & Rowhill con vol \\
\hline Dean Green Team Volunteers & Royal Horticultural Society \\
\hline Dedham Vale AONB and Stour Valley Project & RSPB \\
\hline Derbyshire con vol & Scarborough con vol \\
\hline DofE & Scottish Wildlife Trusts \\
\hline Dorset AONB Partnership & Scouts \\
\hline Durham Uni con vol & SeaSchool \\
\hline Durlston Volunteers & Sheffield W'experience programmes \\
\hline Earth Trust & Shropshire Hills AONB \\
\hline East Devon AONB Partnership & Silvanus Trust \\
\hline Egham/Staines con vol & Small Woods Association \\
\hline Environment Kernow & SNCV (Sutton) \\
\hline Epping forest con vol & $\mathrm{SNH}$ \\
\hline Europarc & Snowdonia Society \\
\hline FEVA & Solway Coast AONB \\
\hline Fleet Pond Soc & Somerset Community Food \\
\hline Forest of Bowland AONB & South Devon AONB Partnership \\
\hline
\end{tabular}


(Continued)

\begin{tabular}{|c|c|}
\hline Forest Research & South Down National Park \\
\hline Forest School & South West Environmental Action Trust \\
\hline Forestry Commission & South West Lakes Trust \\
\hline Forestry Commission Scotland & South West London Environment Network \\
\hline Forum for Environmental Volunteering Activity & Steeple Woodland Reserve \\
\hline Friends of Par Beach & Suffolk Coast \& Heaths AONB Partnership \\
\hline Friends of the earth & Surfers Against Sewage \\
\hline Frimley Fuel Allot con team & Surrey Hills AONB \\
\hline Froglife & Sustrans \\
\hline Gibbonsdown and Court Partnership & Tamar Valley AONB Partnership \\
\hline Glentress Trail Fairies & Teignbridge vols \\
\hline Global Boarders & TFL volunteers \\
\hline Gloucester vale con vol & Thames 21 \\
\hline Gower AONB & The Mendip Society \\
\hline Green Space Community Network & THRIVE \\
\hline Green Team & Venture Scotland \\
\hline Greener Ilfracombe & vInspired \\
\hline Greenham and Crookham con vol & Volunteer Bristol \\
\hline Greenpeace Cornwall & Volunteer Cornwall \\
\hline Groundwork & Volunteer development Scotland \\
\hline Guernsey con vol & Wandle Trust \\
\hline Haldon Forest Volunteers & Wednesday con vol \\
\hline Haldon4Horses & West Country Rivers Trust \\
\hline Hampshire con vol & Wicken Fen con vol \\
\hline
\end{tabular}

Participation in environmental enhancement and conservation activities for health and well-being in adults (Protocol)

Copyright @ 2013 The Cochrane Collaboration. Published by John Wiley \& Sons, Ltd. 
(Continued)

\begin{tabular}{ll}
\hline Harlow con vol & Wildlife Trust \\
\hline Haven Holidays & Wirral county vols \\
\hline High Weald AONB JAC & Woodland Trust \\
\hline Highland Environmental Network & Wychwood Project \\
\hline Hill Holt Wood & Wycombe District Council \\
\hline Howardian Hills AONB & Wye Valley AONB \\
\hline
\end{tabular}

\section{Appendix 6. Website hand searches}

\section{Terms:}

1. Environment;

2. Conservation;

3. (1) and (2);

4. Environmental enhancement;

5. Volunteering; and

6. Health/well-being.

\begin{tabular}{|c|c|}
\hline Website URL & Website Name \\
\hline http://www.dtic.mil/whs/directives/index.html & US Military DoD \\
\hline http://www.ccw.gov.uk/default.aspx & Countryside Council for Wales \\
\hline http://www.tsrc.ac.uk/ & Third Sector Research \\
\hline http://www.vssn.org.uk/ & Voluntary Sector Studies Network - Journal \\
\hline http://www.ivr.org.uk/ivr-evidence-bank? q=\&t $\% 5 B \% 5 D=362$ & Institute for Volunteer Research \\
\hline http://www.naturaleconomynorthwest.co.uk/ & Natural Economy North West \\
\hline http://www.oecd-ilibrary.org/;jsessionid=136d54v2tehqa.delta & OECD iLibrary \\
\hline $\begin{array}{l}\text { http://www.oecd.org/department/ } \\
0,3355 \text {,en'2649'33713'1 } 1^{\prime} \cdot 1^{\prime} \cdot{ }^{\prime} 1,00 . \text { html }\end{array}$ & OECD Environmental Directorate \\
\hline http://www.epa.gov/ & US Environmental Protection Agency \\
\hline http://hero.epa.gov/index.cfm & Health and Environmental Research Online - US \\
\hline
\end{tabular}




\section{(Continued)}

\begin{tabular}{|c|c|}
\hline http://www.eea.europa.eu/ & European Environment Agency \\
\hline http://www.npca.org/ & US National Parks Conservation \\
\hline http://www.environment.gov.au/ & Australian Environment Agency \\
\hline http://www.ec.gc.ca/default.asp?lang=en & Environment Canada \\
\hline http://www.npws.ie/ & Ireland Parks \\
\hline http://www.epa.ie/ & Environmental Protection Ireland \\
\hline http://www.doeni.gov.uk/niea/ & Dept of Env Ireland \\
\hline http://www.epa.govt.nz/Pages/default.aspx & NZ EPA \\
\hline http://www.doc.govt.nz/publications/ & NZ Conservation Authority \\
\hline http://www.forestry.gov.uk/publications & Forestry Commission \\
\hline http://www.forestry.gov.uk/forestresearch & Forest Research \\
\hline http://www.snh.gov.uk/publications-data-and-research/ & Scottish Natural Hertitage \\
\hline http://www.feva-scotland.org/display/library & FEVA \\
\hline http://publications.naturalengland.org.uk/ & Natural England \\
\hline http://www.sehn.org/ & Science and Environmental Health Network \\
\hline http://www.sustainweb.org/publications/ & Sustain Web \\
\hline http://www.fph.org.uk/policy\%2c publications and 'events & Faculty of Public Health College - London \\
\hline http://www.carefarminguk.org/case-studies.aspx & Care Farming UK \\
\hline $\begin{array}{l}\text { http://www.mod.uk/DefenceInternet/MicroSite/DIO/ } \\
\text { OurPublications/EstateAndSustainableDevelopment/ } \\
\text { Sanctuary.htm }\end{array}$ & Sanctuary Magazine, MoD UK \\
\hline http://www.hphpcentral.com & International 'healthy parks healthy people' network \\
\hline http://www.ecohealth.net & International association for ecology and health \\
\hline $\begin{array}{l}\text { http://www.ramsar.org/cda/en/ramsar-pubs/main/ramsar/1- } \\
300^{\circ} 4000^{\circ} \cdot\end{array}$ & $\begin{array}{l}\text { Healthy wetlands and healthy people initiative of Ramsar Con- } \\
\text { vention on Wetlands }\end{array}$ \\
\hline
\end{tabular}




\section{Appendix 7. Tools for critical appraisal}

The Cochrane Collaboration's tool for assessing risk of bias

\begin{tabular}{|c|c|c|}
\hline Domain & Description & Review authors' judgement \\
\hline Sequence generation. & $\begin{array}{l}\text { Describe the method used to generate the } \\
\text { allocation sequence in sufficient detail to } \\
\text { allow an assessment of whether it should } \\
\text { produce comparable groups }\end{array}$ & $\begin{array}{l}\text { Was the allocation sequence adequately } \\
\text { generated? }\end{array}$ \\
\hline Allocation concealment. & $\begin{array}{l}\text { Describe the method used to conceal the } \\
\text { allocation sequence in sufficient detail to } \\
\text { determine whether intervention allocations } \\
\text { could have been foreseen in advance of, or } \\
\text { during, enrolment }\end{array}$ & Was allocation adequately concealed? \\
\hline $\begin{array}{l}\text { Blinding of participants, personnel and } \\
\text { outcome assessors Assessments should be } \\
\text { made for each main outcome (or class of out- } \\
\text { comes). }\end{array}$ & $\begin{array}{l}\text { Describe all measures used, if any, to blind } \\
\text { study participants and personnel from } \\
\text { knowledge of which intervention a partici- } \\
\text { pant received. Provide any information re- } \\
\text { lating to whether the intended blinding was } \\
\text { effective }\end{array}$ & $\begin{array}{l}\text { Was knowledge of the allocated inter- } \\
\text { vention adequately prevented during the } \\
\text { study? }\end{array}$ \\
\hline $\begin{array}{l}\text { Incomplete outcome data Assessments } \\
\text { should be made for each main outcome (or } \\
\text { class of outcomes). }\end{array}$ & $\begin{array}{l}\text { Describe the completeness of outcome data } \\
\text { for each main outcome, including attri- } \\
\text { tion and exclusions from the analysis. State } \\
\text { whether attrition and exclusions were re- } \\
\text { ported, the numbers in each intervention } \\
\text { group (compared with total randomized } \\
\text { participants), reasons for attrition/exclu- } \\
\text { sions where reported, and any re-inclusions } \\
\text { in analyses performed by the review authors }\end{array}$ & $\begin{array}{l}\text { Were incomplete outcome data adequately } \\
\text { addressed? }\end{array}$ \\
\hline
\end{tabular}


Selective outcome reporting.

Other sources of bias.

Derived from Higgins 2011
State how the possibility of selective out- Are reports of the study free of suggestion come reporting was examined by the review of selective outcome reporting? authors, and what was found

State any important concerns about bias Was the study apparently free of other probnot addressed in the other domains in the lems that could put it at a high risk of bias? tool

If particular questions/entries were prespecified in the review's protocol, responses should be provided for each question/entry

EPHPP quality assessment tool (quantitative studies)

\section{A. Selection bias}

(Q1) Are the individuals selected to participate in the study likely to be representative of the target population?

(Q2) What percentage of selected individuals agreed to participate?

\section{B. Study design}

Indicate the study design.

Was the study described as randomized?

If Yes, was the method of randomization described?

If Yes, was the method appropriate?

\section{Confounders}

(Q1) Were there important differences between groups prior to the intervention?

(Q2) If yes, indicate the percentage of relevant confounders that were controlled (either in the design (e.g. stratification, matching) or analysis)?

\section{Blinding}

(Q1) Was (were) the outcome assessor(s) aware of the intervention or exposure status of participants?

(Q2) Were the study participants aware of the research question?

\section{E. Data collection methods}

(Q1) Were data collection tools shown to be valid?

(Q2) Were data collection tools shown to be reliable? 


\section{F. Withdrawals and drop-outs}

(Q1) Were withdrawals and drop-outs reported in terms of numbers and/or reasons per group?

(Q2) Indicate the percentage of participants completing the study. (If the percentage differs by groups, record the lowest).

\section{G. Intervention integrity}

(Q1) What percentage of participants received the allocated intervention or exposure of interest?

(Q2) Was the consistency of the intervention measured?

(Q3) Is it likely that subjects received an unintended intervention (contamination or co-intervention) that may influence the results?

\section{H. Analyses}

(Q1) Indicate the unit of allocation

(Q2) Indicate the unit of analysis

(Q3) Are the statistical methods appropriate for the study design?

(Q4) Is the analysis performed by intervention allocation status (i.e. intention to treat) rather than the actual intervention received?

\section{Global rating for this paper (circle one):}

1 STRONG (no WEAK ratings)

2 MODERATE (one WEAK rating)

3 WEAK (two or more WEAK ratings)

With both reviewers discussing the ratings:

Is there a discrepancy between the two reviewers with respect to the component (A-F) ratings?

If yes, indicate the reason for the discrepancy

Final decision of both reviewers (circle one):

1 STRONG

2 MODERATE

3 WEAK

\section{Wallace criteria}

\begin{tabular}{|c|c|c|c|}
\hline 1 & Question & Is the research question clear? & $\mathrm{E}$ \\
\hline 2 & Theoretical Perspective & $\begin{array}{l}\text { Is the theoretical or ideological perspective of the } \\
\text { author (or funder) explicit, and has this influ- } \\
\text { enced the study design, methods or research find- } \\
\text { ings? }\end{array}$ & $\mathrm{D}$ \\
\hline 3 & Study Design & $\begin{array}{l}\text { Is the study design appropriate to answer the } \\
\text { question? }\end{array}$ & $\mathrm{E}$ \\
\hline
\end{tabular}

Participation in environmental enhancement and conservation activities for health and well-being in adults (Protocol) 


\begin{tabular}{|c|c|c|c|}
\hline 4 & Context & Is the context or setting adequately described? & \\
\hline 5 & Sampling & $\begin{array}{l}\text { (Qualitative) Is the sample adequate to explore } \\
\text { the range of subjects and settings, and has it been } \\
\text { drawn from an appropriate population? } \\
\text { (Quantitative) Is the sample size adequate for the } \\
\text { analysis used and has it been drawn from an ap- } \\
\text { propriate population? }\end{array}$ & $\mathrm{E}$ \\
\hline 6 & Data Collection & $\begin{array}{l}\text { Was the data collection adequately described and } \\
\text { rigorously conducted to ensure confidence in the } \\
\text { findings? }\end{array}$ & $\mathrm{E}$ \\
\hline 7 & Data Analysis & $\begin{array}{l}\text { Was there evidence that the data analysis was rig- } \\
\text { orously conducted to ensure confidence in the } \\
\text { findings? }\end{array}$ & $\mathrm{E}$ \\
\hline 8 & Reflexivity & $\begin{array}{l}\text { Are the findings substantiated by the data and } \\
\text { has consideration been given to any limitations } \\
\text { of the methods or data that may have affected the } \\
\text { results? }\end{array}$ & $\mathrm{D}$ \\
\hline 9 & Generalisability & $\begin{array}{l}\text { Do any claims to generalisability follow logically, } \\
\text { theoretically and statistically from the data? }\end{array}$ & $\mathrm{D}$ \\
\hline 10 & Ethics & $\begin{array}{l}\text { Have ethical issues been addressed }{ }^{*} \text { and confi- } \\
\text { dentiality respected? }\end{array}$ & $\mathrm{D}$ \\
\hline
\end{tabular}

\section{CONTRIBUTIONS OF AUTHORS}

RG is the lead reviewer and will lead all aspects of the review. KH and RL are co-reviewers and will screen, appraise, extract, and approve the final synthesis of the review. CC will develop the search strategy and conduct bibliographic searches. 


\section{DECLARATIONSOF INTEREST}

There are no competing interests from any of the review team.

\section{SOURCES OF SUPPORT}

\section{Internal sources}

- University of Exeter, UK.

Internal salary support

\section{External sources}

- National Institute for Health Research (NIHR) School for Public Health Research (SPHR), UK.

Salary support (all research staff) and other research costs

- National Institute for Health Research Collaborations for Leadership in Applied Health Research and Care, UK. Salary support (RG)

- European Regional Development Fund, UK.

Salary support (RG)

- European Social Fund Convergence Programme for Cornwall and the Isles of Scilly, UK.

Salary support (RG) 